\title{
Prevalência de Staphylococcus aureus no parto em vacas mestiças criadas sob regime semi intensivo de produção leiteira
}

\author{
Pricilla Pozzati $^{1 *}$, Fernando Passon Casagrande ${ }^{2}$, Fabiola de Oliveira Paes Leme ${ }^{3}$ \\ ${ }^{1}$ Mestre pelo Departamento de Clínica e Cirurgia da Escola de Veterinária da Universidade Federal de Minas \\ Gerais. Belo Horizonte, Minas Gerais.pri.medvet@yahoo.com.br* \\ 2 Professor Doutor do Departamento de Anatomia, Patologia e Clínicas Veterinárias da Escola de Veterinária \\ da Universidade Federal da Bahia. Salvador, Bahia. passoncasagrande@hotmail.com \\ ${ }^{3}$ Professora Doutora do Departamento de Clínica e Cirurgia da Escola de Veterinária da Universidade Federal \\ de Minas Gerais.Belo Horizonte, Minas Gerais. fabiola.ufmg@gmail.com
}

RESUMO. Amostras de leite foram coletadas de 25 vacas mestiças, pluríparas, a fim de realizar cultura bacteriana. A prevalência de Staphylococcus aureus encontrada em 25 vacas no momento do parto foi de $56 \%$. Os resultados indicam a necessidade de controle e implementação de métodos de prevenção e mastite infecciosa.

Palavras chave: Mastite, leite, isolamento, bactérias

\section{Staphylococcus aureus prevalence in childbirth in crossbred cows raised in semi - intensive system of milk production}

\begin{abstract}
Milk samples were collected from 25 crossbred cows, pluriparous in order to perform bacterial culture. The prevalence of Staphylococcus aureus found in 25 cows at delivery was $56 \%$. The findings indicate the need of control and implementation of methods for prevention and infectious mastitis.
\end{abstract}

Keywords: mastitis, milk, isolation, bacteria

\section{Introdução}

Mastite é a inflamação do parênquima mamário causada por microrganismos em sua maioria bactérias que se multiplicam no interior da glândula mamária e produzem toxinas sendo algumas vezes não detectada sem testes diagnósticos complementares (Radostitis et al., 2007).

A mastite clínica ocorre quando há o aparecimento de sintomas como secreções anormais, grumos no leite, desidratação, depressão da vaca e perda de apetite. Já na mastite subclínica o animal não apresenta sinais visíveis da doença que somente é diagnosticada quando são realizados exames complementares como a cultura bacteriana do leite ou secreção (Radostits et al., 2007).

Durante todo o período de lactação, as vacas ficam sujeitas às alterações do ambiente, à exposição dos quartos saudáveis aos microorganismos durante o processo de ordenha (Radostits et al., 2007) e a contaminação entre animais (Keefe, 2012). A maioria das novas infecções ocorre durante a fase inicial do período de secagem da vaca ou nos dois primeiros meses de lactação (Radostits et al., 2007).

Apesar de existirem mais de 100 espécies microbianas possivelmente presentes na glândula mamária, somente uma pequena quantidade de microorganismos é importante para o surgimento da maioria dos casos de mastite clínica e subclínica sendo os agentes mais importantes as bactérias Streptococcus agalactiae, Staphylococcus aureus e Mycoplasmabovis (Quinn et al., 2005).

Barbalho \& Mota (2001) afirmaram que todas as propriedades visitadas em seu estudo possuíam alto índice de animais com a doença na forma subclínica sendo encontrado Staphylococcus aureus como o agente isolado com maior frequência, fato descrito também por Ferreiro et al. (1981), sendo necessária a adoção de práticas para redução da incidência e prevalência aos níveis aceitáveis (Sommerhauser et al., 2003).

A prevalência desse patógeno isolado na região da Zona da Mata em Minas Gerais foi de 
30,49\% segundo Ferreiro et al. (1981) para vacas em lactação, em diferentes períodos de lactação. Porcionato et al. (2010) afirmaram que há uma prevalência de $25,22 \%$ dos quartos mamários infectados por Staphylococcus aureus em 80 vacas Gir no terço médio-final da lactação provenientes da Empresa de Pesquisa Agropecuária de Minas Gerais (EPAMIG) em Uberaba, Minas Gerais e do Instituto de Ciência Animal de São Paulo. Andrade et al. (1998) encontraram prevalência de $30,2 \%$ em vacas holandesas de diferentes idades e estágio de lactação em 25 propriedades leiteiras no estado de Goiás que utilizam ordenhadeiras mecânicas. Martins et al. (2010) mostraram a prevalência de $21,5 \%$ e $44 \%$ em vacas com mastite subclínica e clínica respectivamente em 108 vacas pertencentes às cinco propriedades leiteiras na microrregião de Cuiabá, MT em diferentes estágios da lactação. No Piauí, Ferreira et al. (2007) relataram a prevalência de $74,6 \%$ para o gênero Staphylococcus após analisarem 852 amostras de leite oriundas de vacas em período médio de lactação.

O S. aureus está comumente associado à mastite crônica devido à habilidade desta bactéria de produzir biofilme que gera uma cápsula, impedindo a ação fagocitária de células do organismo por neutrófilos. Outros mecanismos de defesa do $S$. aureus são a indução de apoptose de leucócitos e formação de abcessos, possibilitando culturas falso-negativas em animais assintomáticos (Rainard et al., 2003).

\section{Material e Métodos}

Foram coletadas amostras de leite de 25 vacas mestiças, pluríparas, provenientes de uma fazenda comercial localizada no distrito de Ibitira, município de Martinho Campos, centrooeste de Minas Gerais, situado a $19^{\circ} 19^{\prime}$ de latitude $\mathrm{S}$ e $45^{\circ} 14^{\prime}$ de longitude $\mathrm{W}$ e com altitude média de 674 metros acima do nível do mar. O número das amostras foi determinado pela utilização do teste de McNemar para avaliação qualitativa do patógeno. Este experimento possuía provação da Comissão de Ética no Uso de Animais da Universidade de Minas Gerais sob o protocolo 358/2012.

Para a realização da coleta, foi precedido o pré-dipping realizado rotineiramente pela fazenda com hipoclorito de sódio a $20 \%$, em seguida, foi realizada a limpeza dos tetos com uma gaze embebida em álcool $70 \%$. Após este procedimento foi realizado o descarte dos três primeiros jatos de leite e posterior armazenamento de $10 \mathrm{~mL}$ de leite em tubos estéreis com tampa rosqueada.

As coletas foram realizadas no dia exato do parto sendo o colostro retirado antes da primeira ordenha pós-parto. Após esse procedimento, o colostro foi congelado para armazenamento e transporte até a Universidade Federal de Minas Gerais para realização do isolamento bacteriano.

Para o isolamento bacteriano, a metodologia utilizada foi a descrita por Kenneth \& Ray (2004) que preconiza o preparo de caldo Müeller Hinton, na proporção de $3 \mathrm{~mL}$ para $200 \mu \mathrm{L}$ de leite a ser testado. Esse caldo foi preparado no momento do uso e mantido à estufa na temperatura de $37^{\circ} \mathrm{C}$. Após oito horas, foi realizada a leitura de $20 \mu \mathrm{L}$ do conteúdo citado anteriormente por microscopia de campo escuro em objetiva de 100x em imersão para identificação da morfologia bacteriana. Após a classificação morfológica foi realizado o plaqueamento das amostras. As devidas placas foram levadas à estufa à $37^{\circ} \mathrm{C}$ por 24 horas.

Ainda segundo Kenneth \& Ray (2004), após o crescimento bacteriano foram realizadas as provas bioquímicas para identificação do microorganismo conforme a classificação de gram positivos e negativos. Para microrganismos gram positivos foram realizadas as provas de catalase, cloreto de sódio $(\mathrm{NaCl})$, hemólise da colônia, arginina, glicerol, orbitol e manitol. Para microrganismos gram negativos foram realizadas as provas de citrato, glicose, gás de glicose, ácido sulfídrico $\left(\mathrm{H}_{2} \mathrm{~S}\right)$, idol, lactose, lisina, manitol, motilidade bacteriana, ornitina, oxidase, salicina, sorbitol, sacarose, uréia e vermelho de metila.

\section{Resultados e Discussão}

Após as leituras das placas, a prevalência de Staphylococcus aureus encontrada em amostras de leite de 25 vacas no parto foi de $56 \%$. Os altos valores encontrados indicam que os métodos de controle e prevenção para mastite infecciosa não estavam sendo adequadamente implementados. Os resultados apresentaram valores menores aos encontrado por Ferreiro et al. (1981), Andrade et al. (1998), Porcionato et al. (2010), Martins et al. (2010), pois a maioria destes autores não trabalharam com vacas no momento do parto, período em que a imunidade dos animais está comprometida pelos vários fatores estressantes deste período resultando em altas concentrações 
de cortisol sanguíneo, o que predispõe os animais a doenças infecciosas.

Ferreira et al. (2007) encontraram alta prevalência $(74,6 \%)$ para o gênero Staphylococcus após analisarem 852 amostras de leite oriundas de vacas em período médio de lactação, porém não fez a identificação das espécies impossibilitando a comparação, já que há várias outras espécies de Staphylococcus que podem causar mastite, porém de fácil tratamento e controle.

Os resultados obtidos reforçam a importância do tratamento direcionados das vacas durante o período seco com o objetivo de reduzir os agentes patógenos de maior prevalência e relevância clínico-epidemiológica.

\section{Conclusão}

A prevalência de Staphylococcus aureus encontrada na fazenda comercial do estado de Minas Gerais foi alta (56\%), sendo necessárias adoções de medidas para redução desse patógeno e consequentemente da perda de produção.

\section{Referências Bibliográficas}

Andrade, M.A.; Mesquita, A.J.; Dias Filho, F.C.D. Jayme, V. S. 1998. Prevalência e etiologia de mastite bovina subclínica em propriedades do estado de goiás que utilizam ordenhadeiras na obtenção do leite. Pesquisa Agropecuária Tropical, 28, 29-42.

Barbalho, T.C.F. \& Mota, R.A. 2001. Isolamento de agentes bacterianos envolvidos em mastite subclínica bovina no Estado de Pernambuco. Revista Brasileira de Saúde e Produção Animal, 2, 31-36.

Kenneth, J.R \& Ray, G.C. 2004. Principles of laboratory diagnosis of infectious diseases. In: Kenneth, J.R \& Ray, G.C. (Ed). Sherris Medical Microbiology - an introduction to infectious diseases. 4. Ed. New York: McGraw-Hill. 229-258p.

Ferreira, J.L.; Lins, J.L.F.H.A.; Cavalcanti, T.V. Macedo, N. A.; Borjas, A. de L. R. 2007. Prevalência e etiologia da mastite bovina no município de Teresina, Piauí. Ciência Animal Brasileira, 8, 261-266.

Ferreiro, L.; Santos, E.C. \& Silva, N. 1981. Ocorrência e etiologia da mastite bovina na zona da mata do estado de minas gerais.
Arquivo da Escola de Veterinária da UFMG, 33, 31-37.

Keefe, G. 2012. Update on control of Staphylococcus aureus and Streptococcus agalactiae for management of mastitis. Veterinary clinics of North America: Food Animal, 28, 203-216.

Martins, R.P.; Silva, J.A.G.; Nakazato, L. Dutra, V.; Filho, E. S. A. 2010. Prevalência e etiologia infecciosa da mastite bovina na microrregião de Cuiabá, MT. Ciência Animal Brasileira, 11, 181-187.

Porcionato, M.A.F.; Soares, W.V.B.; Cortinhas, C.S.; Mestieri, L.; Santos, M. V. 2010. Milk flow, teat morphology and subclinical mastitis prevalence in gir cows. Pesquisa Agropecuária Brasileira, 45, 1505-1512.

Radostitis, O. M.; Gay, C. C.; Hinchcliff, K.W.; Constable, P. D. 2007. Veterinary Medicine. 10. Ed. Elsevier: London, 673-696p.

Rainard, P.; Corrale,S J.C.; Barrio, M.B.; Cochard, T.; Poutrel, B. 2003. Leucotoxic activities of Staphylococcus aureus strains isolated from cows, ewes, and goats with mastitis: importance of Luk M/LukF'-PV leukotoxin. Clinical and Diagnostic Laboratory Immunology, 10, 272.

Sommerhauser, J.; Kloppert, B.; Wolter, W.; Zschöck, M.; Sobiraj, A.; Failing, K. 2003. The epidemiology of staphylococcus aureus infections from subclinical mastitis in dairy cows during a control programme. Veterinary Microbiology, 96, 91-102.

Quinn, P.J.; Markey, B.K.; Couter, M.E.. Donnelly, W.J.; Leonard, F.C. 2005. Microbiologia veterinária e doenças infecciosas. 1.ed. Porto Alegre: Artmed, 451$460 \mathrm{p}$.

Recebido em Dezembro 4, 2014.

Aceito em Maio 28, 2015

License information: This is an open-access article distributed under the terms of the Creative Commons Attribution License, which permits unrestricted use, distribution, and reproduction in any medium, provided the original work is properly cited. 